\title{
Treatment of osteonecrosis of the femoral head with focal anatomic-resurfacing implantation (HemiCAP): preliminary results of an alternative option
}

Onur Bilge ${ }^{1 *}$, Mahmut Nedim Doral $^{2}$, Mustafa Yel ${ }^{1}$, Nazim Karalezli ${ }^{1}$ and Anthony Miniaci ${ }^{3}$

\begin{abstract}
Background: The optimal treatment of osteonecrosis of the femoral head has not been established yet. The aim of this study was to report preliminary clinical results of focal anatomic-resurfacing implantation for the treatment of osteonecrosis of the femoral head.

Methods: Five patients (four male, one female) with seven surgical procedures, ages between 37 and 52 with an average age of $45.2(+/-7.2)$, diagnosed as femoral head avascular necrosis and who were unresponsive to conservative management or had failed previous surgical treatments were treated with a focal anatomic femoral head resurfacing between the years 2011-2012 and were retrospectively reviewed. Five patients with at least two years of follow-up, one left hip, two right hips, and two patients with bilateral hip surgery were included in this review. After safe surgical dislocation of the hip, full exposure of the femoral head was established. A focalresurfacing implant matching patient anatomy and femoral head curvature was performed accordingly. Neither intraoperative or postoperative complications nor revision ensued. Visual analogue scores and Harris Hip Scores were recorded both preoperatively and at postoperative 2 years for all seven surgeries.

Results: The mean follow-up period was $26.6+/-3.8$ months, with a range between 24-33 months. The mean visual analogue scores were $8.9+/-0.9$ preoperatively and $2.3+/-1.0$ postoperatively at year two $(p=0.017)$. Harris Hip Scores at postoperative follow-up were found to improve significantly from good to excellent scores (86.0 +/- 7.9), compared with preoperative poor scores $(26.7+/-11.8)(p=0.018)$. The clinical improvements in visual analogue scores (VAS) and Harris Hip Scores were also found to correlate with each other $(p<0.05)$.

Conclusions: In the present study, the alternative technique of focal anatomic hip resurfacing with HemiCAP® yielded preliminary successful results for the treatment of osteonecrosis of the femoral head. To the best of our knowledge, this is the first case series in the literature, reporting functional clinical results with the use of a focal anatomic-resurfacing implant for the treatment of focal femoral head osteonecrosis.
\end{abstract}

Keywords: Femoral head, Osteonecrosis, Hip, Focal anatomic-resurfacing, Implantation

\footnotetext{
* Correspondence: onurbilgemd@gmail.com

'Department of Orthopaedics and Traumatology, Konya Necmettin Erbakan

University, Meram Faculty of Medicine, Meram 42080, Konya, Turkey

Full list of author information is available at the end of the article
} 


\section{Background}

Osteonecrosis $(\mathrm{ON})$ of the femoral head is a painful, progressive, and potentially debilitating disease, which affects patients in their third to fifth decades of life [1-3]. A variety of risk factors have been identified in the literature including trauma, alcohol abuse, chronic corticosteroid use, and coagulation disorders [4]. Although ischemia, direct cellular toxicity and altered differentiation of mesenchymal stem cells were postulated mechanisms of pathogenesis, the exact etiology and pathogenesis are still not certain $[3,5]$.

Early diagnosis before collapse occurs is important in order to prevent subsequent collapse and osteoarthritis. The diagnosis requires a high index of suspicion, especially in the earliest stages. Deep groin pain is the most common early symptom. Limitation of range of motion (ROM) (especially internal rotation) is mostly evident at later stages. In general, the diagnosis is made by radiography and magnetic resonance imaging (MRI). MRI seems to be the best diagnostic tool with the highest sensitivity and specificity [6,7]. Moreover, MRI is the mainstay of all classification systems to stage $\mathrm{ON}$, which currently guide treatment decisions and have prognostic importance. The two most commonly used classification systems are Ficat \& Arlet, Ficat and Steinberg University of Pennsylvania [8-11]. The extent of the necrotic portion of the femoral head, which was also found to be a prognostic factor for collapse, could be measured with modified Kerboul method [12].

The treatment has been mostly based on the stage, extent, location, and cause of the $\mathrm{ON}$ together with the age of the patient. Currently, there are two main approaches for treatment: non-operative and operative. Both aim to relieve pain, to improve function, and to prevent progression to some extent. A variety of modalities have been described for the non-operative management of hip osteonecrosis in the literature including nonweight bearing, non-steroidal anti-inflammatory drugs, extra-corporeal shock wave treatment, pulsed electromagnetic therapy, and hyperbaric oxygen [13-21]. Many of these conservative treatments may only have a role in the early pre-collapse stages of the disease, with questionable limited success.

Currently, surgical treatment of $\mathrm{ON}$ of the femoral head includes the following: percutaneous drilling, core decompression with or without bone grafting, biological additions (stem cells, platelet rich plasma etc.), vascularized bone grafting, tantalum rods, proximal femoral osteotomies, and hip arthroplasties [22-32]. Although it seems that the most promising results were obtained with total hip arthroplasty, the optimal treatment for $\mathrm{ON}$ of the femoral head has not yet been established especially in young and middle-aged people $[3,4]$.

The aim of this study was to report preliminary clinical outcomes of focal resurfacing implantation for $\mathrm{ON}$ of the femoral head as an alternative option of jointpreserving surgery of the hip. To the best of our knowledge, this is the first case series regarding the use of an alternative focal anatomic-resurfacing implant $\left(\mathrm{HemiCAP}^{\circ}\right)$ for $\mathrm{ON}$ of the femoral head.

\section{Methods}

\section{Patients}

This study comprised a retrospective review of prospectively collected data for seven hips of five patients (four male, one female). The average age of the patients was 45.2 years (range 37-52 years). The demographic features of the patients are presented in Table 1. All patients presented with severe hip pain and limitation in hip ROM. The patients were diagnosed as Ficat-Arlet stage IIB, III, or IV femoral head avascular necrosis (two hips IIB, four hips III, one hip IV). Radiological imaging with X-ray and MRI of a patient with bilateral osteonecrosis of femoral head are shown in Figures 1 and 2. All the patients were unresponsive to non-surgical methods for at least one year. Two patients had previous

Table 1 Demographic features of patients

\begin{tabular}{|c|c|c|c|c|c|c|}
\hline Patient number & Age & Sex & Previous managements & Risk factors & Surgical side & Ficat-Arlet stage \\
\hline \multirow[t]{2}{*}{1} & 48 & Male & Conservative & Hodgkin's Lymphoma & $\mathrm{R}$ & III \\
\hline & & & & Steroid use & $\mathrm{L}$ & III \\
\hline \multirow[t]{3}{*}{2} & 51 & Female & Conservative, core decompression & Breast cancer & $\mathrm{R}$ & $\| B$ \\
\hline & & & & Radiotherapy & & \\
\hline & & & & Steroid use & & \\
\hline \multirow[t]{2}{*}{3} & 37 & Male & Conservative, core decompression & ITP & $\mathrm{L}$ & III \\
\hline & & & & Steroid use & $\mathrm{R}$ & IV \\
\hline \multirow[t]{2}{*}{4} & 52 & Male & Conservative, core decompression & Bronchial asthma & $\mathrm{R}$ & III \\
\hline & & & & Steroid use & & \\
\hline 5 & 38 & Male & Conservative & Alcohol abuse & $\mathrm{R}$ & $\| B$ \\
\hline
\end{tabular}

R: Right, L: Left, ITP: Idiopathic Thrombocytopenic Purpura. 


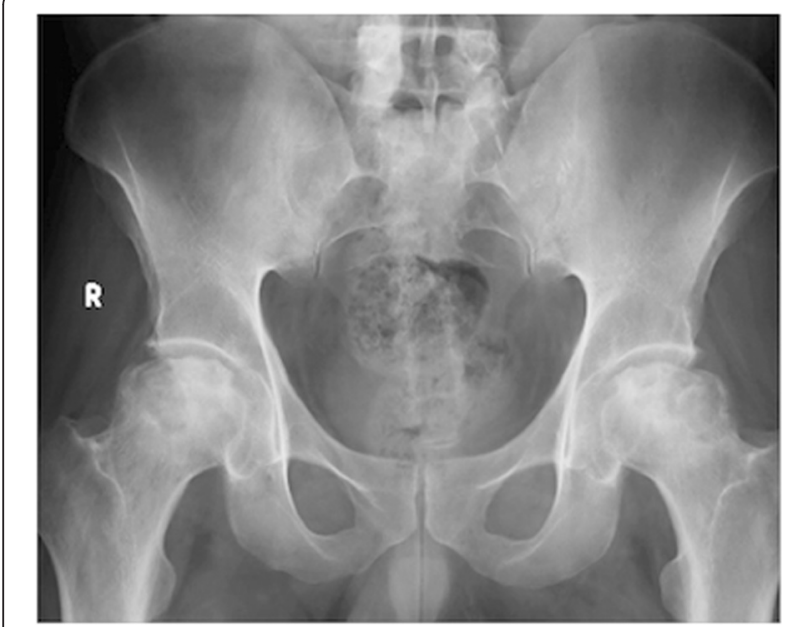

Figure 1 Preoperative X-ray. Anteroposterior pelvis X-ray demonstrating bilateral $\mathrm{ON}$ of the femoral head.

core decompression, which eventually failed. After informed consent for surgery, patients were informed that the data would be reviewed for research. This study was also approved by the local Medical Ethics Committee.

\section{Surgical technique}

Informed consent was obtained from all patients discussing risks and complications including the possibility of conversion to total hip arthroplasty in the case of poor bone quality or fracture. None of the cases had to have a total hip arthroplasty. The seven surgeries were performed with the standard technique with a lateral approach and trochanteric flip osteotomy. Following perioperative prophylaxis with antibiotics and identification of the correct extremity, patients had spinal anesthesia and were placed in a lateral decubitus position. The

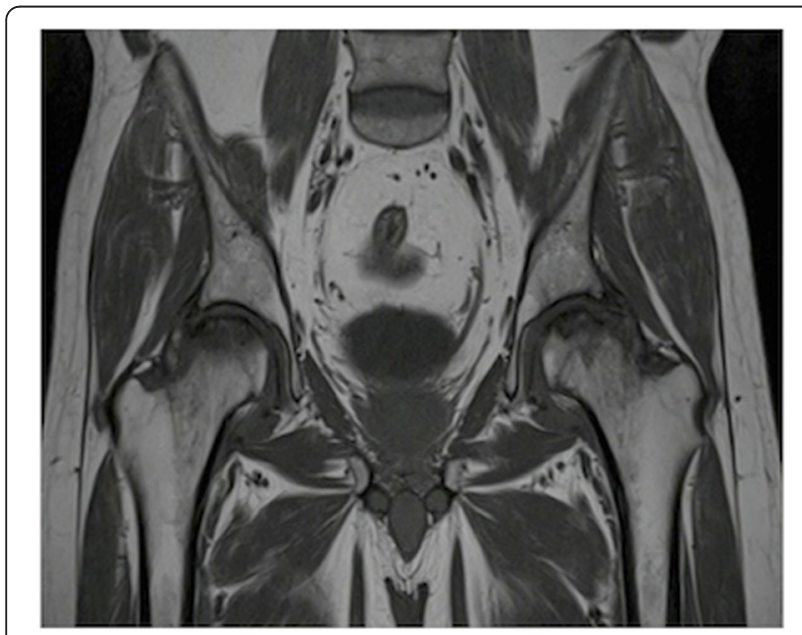

Figure 2 Preoperative MRI scan. T1-weighted coronal MRI scan demonstrating bilateral $\mathrm{ON}$ of the femoral head. surgical site was prepared and draped in a standardized sterile manner. Surgical dislocation of the hip was performed following a direct lateral approach to the hip and trochanteric flip osteotomy as described by Ganz et al. [33]. The hip was dislocated anteriorly with full vision of the femoral head and neck.

Firstly, the borders of the affected softened cartilage overlying the focal osteonecrotic area were determined. A femoral head osteoplasty was performed if necessary due to impingement. Then, a K-wire is passed through the sizing jig covering the entire lesion, into the center of the predetermined osteonecrotic area. After the debridement of this area by using a power drill over the guide $\mathrm{K}$-wire, with simultaneous lavage, the tapered titanium screw was inserted securely by the screwdriver, following a proper taping over the guide K-wire. A contact probe was used in order to size the medial, lateral, anterior, and posterior contours correctly. There are seven different offset sizes available. After the final trial and surface reaming, an anatomically fit sized, $35 \mathrm{~mm}$ diameters, final implant was fixed on the pre-implanted titanium screw - approximately $0.5 \mathrm{~mm}$ below the peripheral healthy articular cartilage surface - with slight tapping with a mallet via an interlocking mechanism. The intraoperative fluoroscopic view was imperative in all cases to see the properly placed focal-resurfacing implant matching the patient's anatomy and femoral head curvature (HemiCAP ${ }^{\circledR}$, Arthrosurface, Franklin, MA) with preservation of the joint space after gentle reduction of the joint. Finally the trochanteric osteotomy was repaired with two $4.5-\mathrm{mm}$ cortical screws. Neither perioperative nor intraoperative complications ensued in any patients (Figures 3, 4, 5, and 6).

It was imperative that good screw fixation was achieved for solid fixation of the implant. In each case, the screw was well fixed and often was difficult to turn into the underlying bone. In no instance was there any concern for fixation. We were prepared to utilize cement if necessary to augment fixation of the screw but this was not necessary.

\section{Postoperative management}

Prophylactic antibiotic, which had been started perioperatively, was continued for 24 hours. Thromboprophylaxis with third generation low molecular weight heparin (Bemiparin, Hibor ${ }^{\mathrm{Tx}}$ ) was started postoperatively at 12 hours and continued for 6 weeks. Neither early nor late postoperative complications ensued. The patients were mobilized with toe-touch weight bearing during the first four weeks, allowing the osteotomized greater trochanter to heal and sufficient implant-bone integration. Thereafter, the mobilization was progressed from partial to full-weight bearing. The osteotomies were healed at two months postoperatively. The screws were removed in two patients, as they 


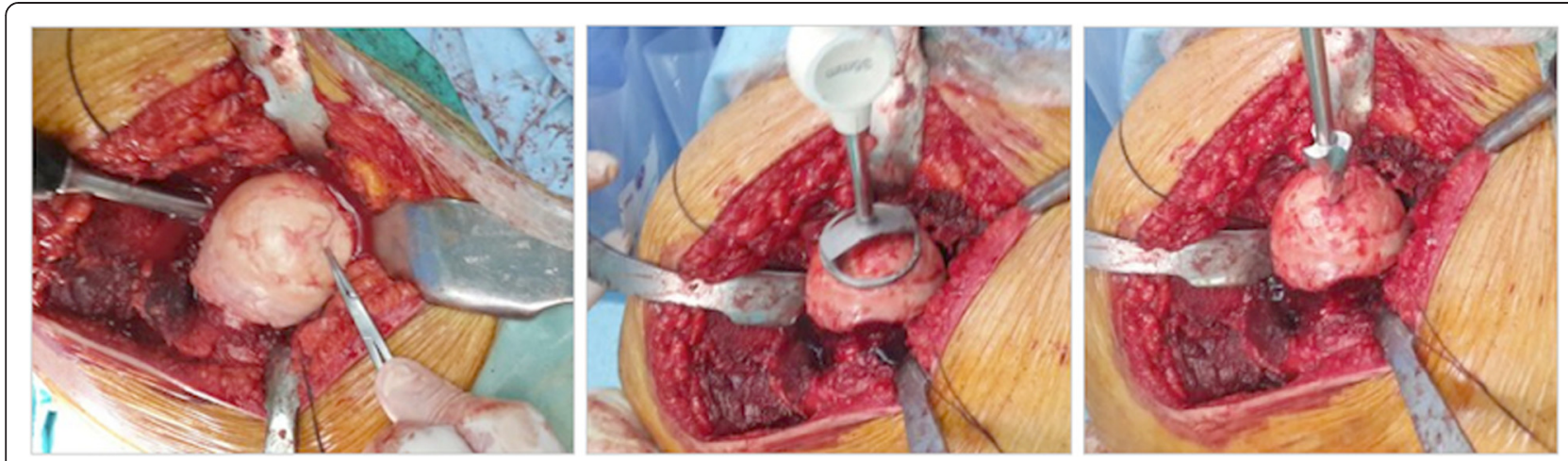

Figure 3 Surgical step 1. Following determination of the borders of the affected softened cartilage overlying osteonecrotic area and femoral head osteoplasty (if necessary due to impingement), a K-wire is passed through the sizing jig, into the center of the predetermined osteonecrotic area, which was debrided by using a power drill, with simultaneous lavage.

became symptomatic. The patients returned back to their daily activities at a mean of three months postoperatively. At final radiological reviews, neither loosening nor subsidence of the implants were observed (Figures 7 and 8). Moreover, no progression of the osteonecrosis, acetabular reaction, head collapse, and progression to osteoarthritis were observed.

\section{Evaluation criteria}

The clinical evaluation of the patients was done by using visual analogue score (VAS) and Harris Hip Score (HHS). These scores were recorded both preoperatively and at postoperative 2 years, for all seven surgeries of five patients. The data were retrospectively reviewed.

\section{Statistical methods}

SPSS version 16.0 was used for statistics. Statistical analyses were performed using the Wilcoxon test and Spearman correlation test, for comparison between preoperative and postoperative values and for correlation of VAS and Harris Hip scores, respectively. The statistical significance was determined at $p$ value $<0.05$.

\section{Results}

The mean follow-up period was $26.6+/-3.8$ months (range 24-33 months). The mean VAS scores were $8.9+/-0.9$ preoperatively and $2.3+/-1.0$ postoperatively at year two $(p=0.017)$. Harris Hip Scores improved from 26.7 preoperatively to 86.0 postoperatively, which were in the good to excellent category $(p=0.018)$. The data were summarized in Table 2 and Figure 9. The preoperative mean scores for pain, functional status, and joint status were $13.6+/-5.6,10.3+/-6.6$, and $2.9+/-1.3$, respectively. The respective values at postoperative $2^{\text {nd }}$ years were $45.0+/-5.2,32.3+/-4.8$, and $8.9+/-0.7$. The lowest items having the poorest scores postoperatively were found to be the following: support, distance walked, and sitting. In addition, the improvements in VAS and Harris Hip Scores were found to correlate significantly with each other $(p<0.05)$.

\section{Discussion}

The most important result of this study was that the use of the focal anatomic-resurfacing implant for the treatment of osteonecrosis of the femoral head yielded
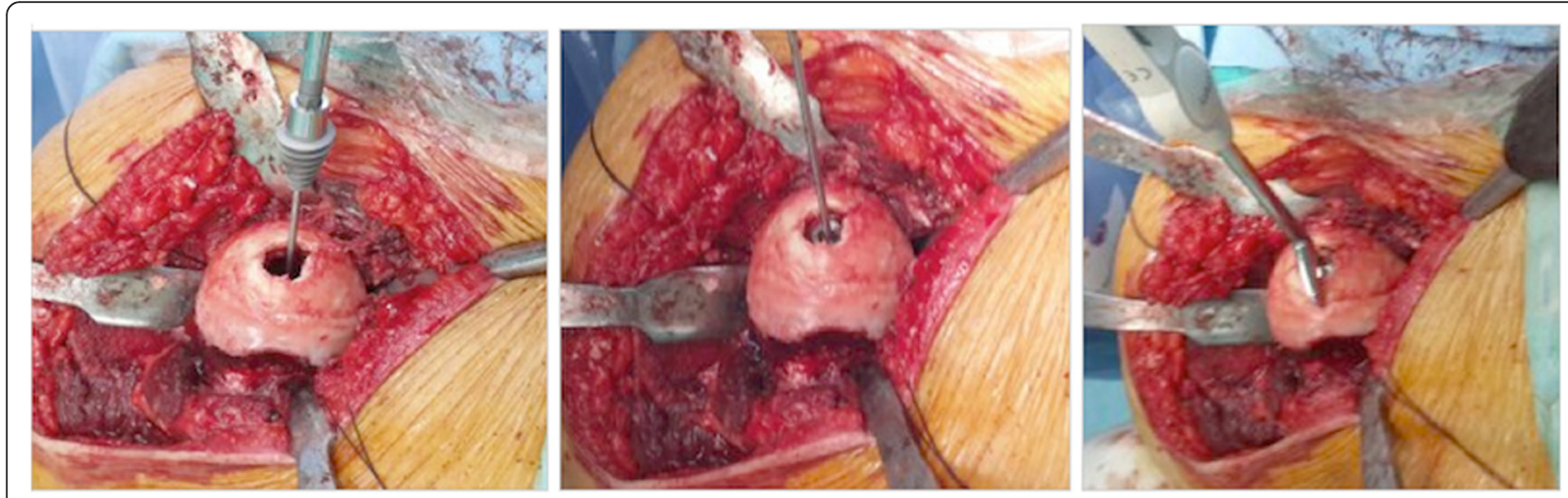

Figure 4 Surgical step 2. Implantation of the tapered titanium screw securely by the screwdriver, after proper taping over the guide K-wire and sizing of the medial, lateral, anterior, and posterior contours with the contact probe. 

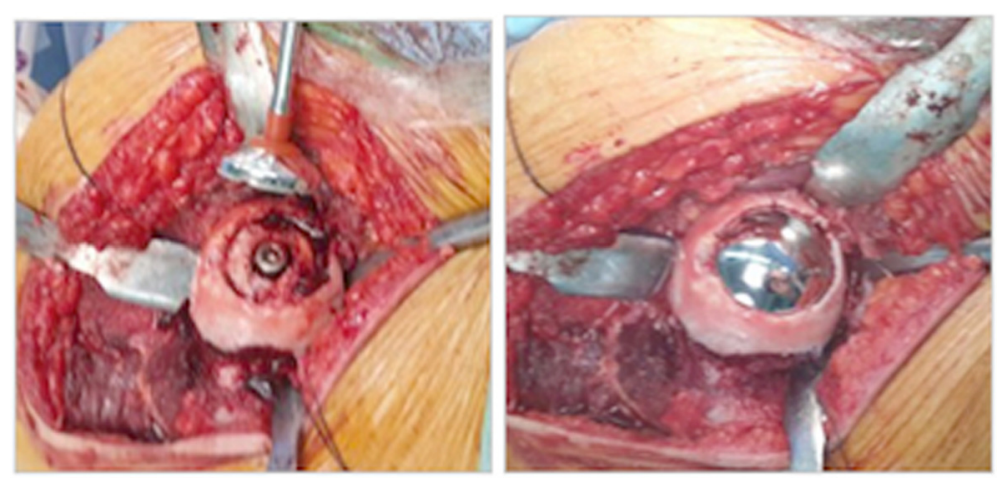

Figure 5 Surgical step 3. Placement of the anatomically fit sized, $35 \mathrm{~mm}$ diameter final implant with slight tapping with a mallet, after trialing and surface reaming. Final view of tapered interlocked CoCrMo articular-resurfacing component, approximately $0.5 \mathrm{~mm}$ below the peripheral healthy articular cartilage surface.

successful preliminary clinical results in seven hips of five patients at a minimum of two years following their surgical procedure. In addition, to the best of our knowledge, this study is the first case series related with the use of this alternative focal anatomic-resurfacing implant for this specific indication.

In general, the management of osteonecrosis of the femoral head consists of non-surgical and surgical methods. Non-surgical modalities such as non-weight bearing, pharmacological (bisphosphonates, anticoagulants, lipidlowering agents, vasodilators), extra-corporeal shock wave treatment, pulsed electromagnetic therapy, and hyperbaric oxygen may have a role only in the early pre-

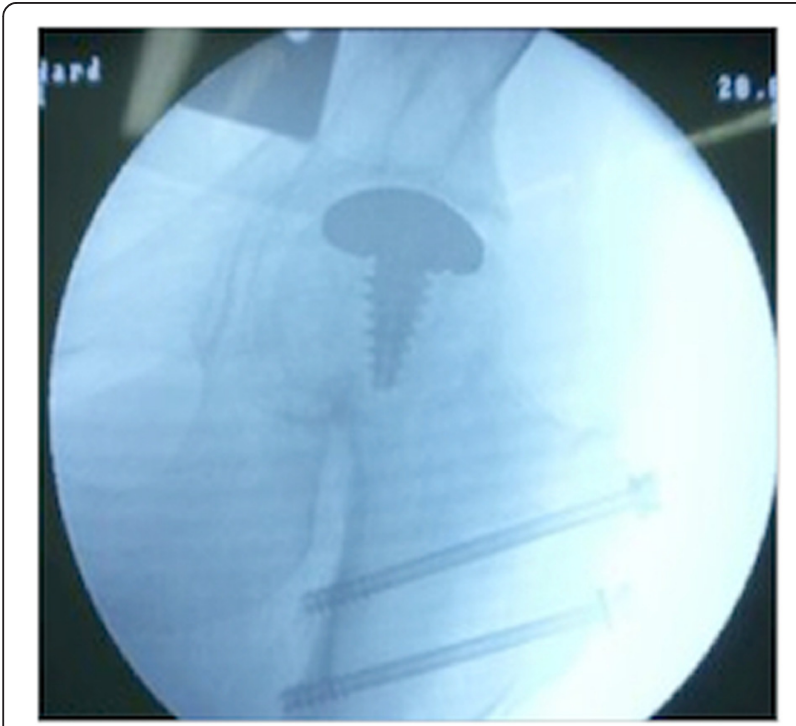

Figure 6 Intraoperative fluoroscopic view. Intraoperative fluoroscopic view showing a properly placed implant (HemiCAP®, Arthrosurface, Franklin, MA) with preservation of the joint space after reduction of the joint and final repair of the trochanteric osteotomy with two 4.5-mm cortical screws. collapse stages of the disease, with a questionable limited success [13-21].

Surgical methods can also be subdivided into two major groups: joint preserving options and total hip arthroplasty. Joint preserving options include the following: percutaneous drilling, core decompression with or without bone grafting, biological procedures (bone marrow stimulation or microfracture, mesenchymal stem cells), vascularized bone grafting, tantalum rods, proximal femoral osteotomies, and hip arthroplasties [22-32].

The most commonly performed surgical method is probably core decompression, which aims to decrease intraosseous pressure and to ameliorate the blood flow to the necrotic area and subsequent healing by creeping substitution. Despite these aims and its use at earlier stages of the disease process, the rate of further additional surgery requirements was reported as high as $80 \%[13,34,35]$. The clinical results of this option had wide variations from $0 \%$ to $91 \%$ [36]. Moreover, Lee et al. found that intertrochanteric osseous pressure was significantly higher after multiple drilling and that these patients had poorer outcomes [37]. Interestingly, this result raises the question of whether the increase in pressure in the intertrochanteric region after core decompression increases the severity of the disease progression or not.

Another viable surgical option is free vascularized bone grafting, which has been advised for earlier stages, before collapse [3,35]. Although successful results were reported at a longer term $[27,38,39]$, it is a highly technical and demanding procedure and is associated with significant donor site morbidities and progression of the osteonecrotic lesion.

When there is a collapse of the lesion, treatment becomes more difficult. Although it seems that the most promising results, especially at late stages, are reported with total hip arthroplasty, the optimal surgical treatment for $\mathrm{ON}$ of the femoral head has not been established, 

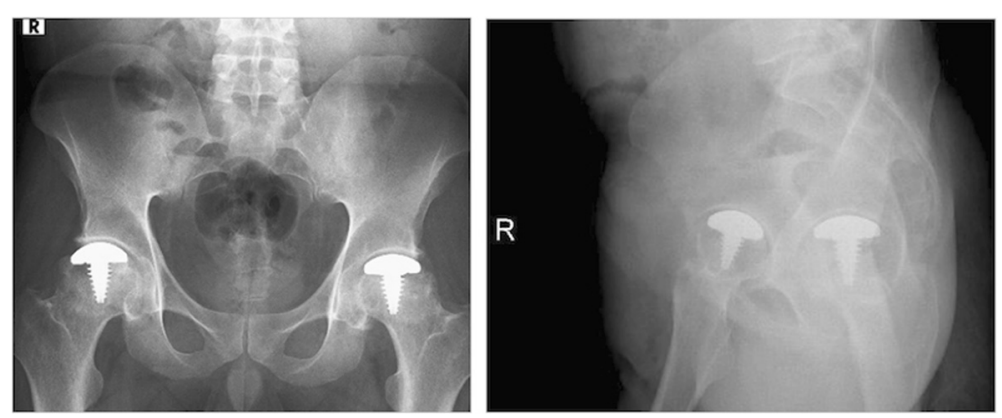

Figure 7 Postoperative X-rays. X-rays at postoperative second years of a 48-year-old male patient. These radiographs show the preservation of the joint spaces without loosening of the implants bilaterally. The screws were removed because of irritation in this patient.

especially in the younger patients [3,4]. The first is the longevity of the implant and is a definite concern [40]. In addition, in contrast to its successful use in patients with primary coxarthrosis, THA was found to have a higher rate of failure in patients with osteoarthritis secondary to osteonecrosis [41,42]. Moreover, the results of THA were reported to be poor in the young age group, which these patients usually are [43-46]. In this context, the importance of hip-preserving surgery has also been stressed in the last decade recently [47]. Under the light of these findings, an alternative treatment option is required in this young age group. Although our study exhibited preliminary results at a mean follow-up of postoperative 26 months, the early results were promising, and we anticipate a better solution in young patients compared with THA, with the advantage of postponing the age for THA. As the number of selected younger patients - with focal ON of the femoral head - who will be treated with the hip HemiCAP increase, the results will be easier to compare with those of THA.

Recently, short-term successful results were obtained with resurfacing arthroplasty in the treatment of osteonecrosis of the femoral head [48]. This procedure preserves bone stock in the femoral head, without compromising subsequent conversion to THA. It can also be used at postcollapse stages in young patients with good bone stock [3]. But, due to reported high revision rates to THA, mostly because of femoral neck fracture, and due to effects of metallic wear debris, most surgeons do not prefer resurfacing arthroplasty for the treatment of $\mathrm{ON}$ of the femoral head [49-51].

Compared with previously discussed alternative techniques, the hip HemiCAP ${ }^{\circ}$ system has some advantages. At first, preoperative planning is not as detailed as total hip arthroplasty. It is a femoral head and jointpreserving surgery in which the patient's own femoral head anatomy is protected to a maximal extent with little bony resection and can be used even in cases of collapse. After the entire exposure of the femoral head, removal of the necrotic area is followed by replacement of the defect by a two-part implant fixed in position with a large threaded screw. This implant matches each patient's anatomy and femoral head contour. They are suitable for young and middle-aged patients with focal lesions. Another advantage is that in case of progression of osteoarthritis, or implant failure or fracture at any time, there is always a chance to revise to primary total hip arthroplasty.

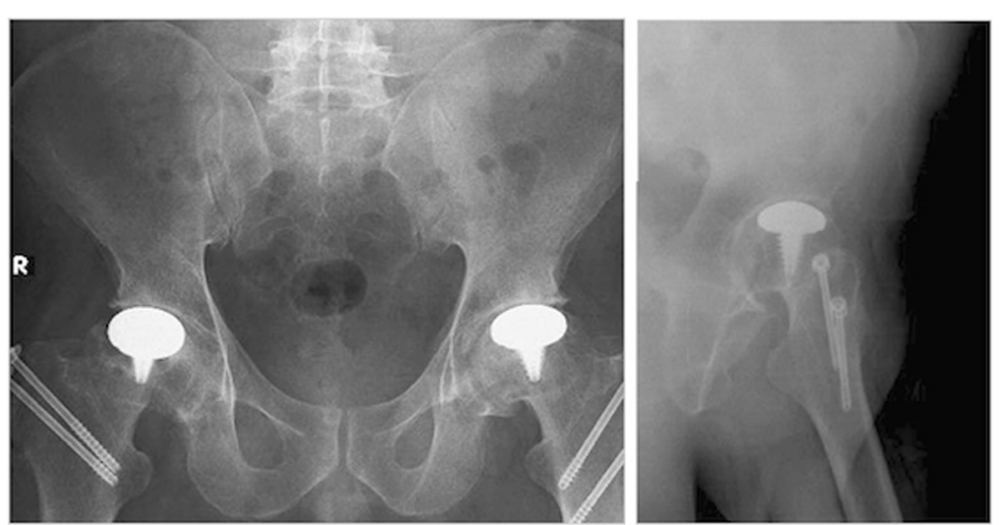

Figure 8 Postoperative $X$-rays. X-rays of a 37-year-old male patient at postoperative $24^{\text {th }}$ months. 
Table 2 Preoperative and postoperative $2^{\text {nd }}$ year VAS and Harris Hip Scores

\begin{tabular}{|c|c|c|c|c|c|}
\hline Patient number & Surgical side & Preoperative VAS & Postoperative VAS & $\begin{array}{l}\text { Preoperative } \\
\text { Harris Hip Score }\end{array}$ & $\begin{array}{l}\text { Postoperative } \\
\text { Harris Hip Score }\end{array}$ \\
\hline \multirow[t]{2}{*}{1} & $\mathrm{R}$ & 10 & 2 & 24 & 84 \\
\hline & L & 8 & 1 & 51 & 94 \\
\hline 2 & $\mathrm{R}$ & 8 & 2 & 22 & 88 \\
\hline \multirow[t]{2}{*}{3} & $\mathrm{R}$ & 10 & 3 & 15 & 87 \\
\hline & L & 9 & 2 & 22 & 86 \\
\hline 4 & $\mathrm{R}$ & 8 & 2 & 32 & 93 \\
\hline \multirow[t]{3}{*}{5} & $\mathrm{R}$ & 9 & 4 & 21 & 70 \\
\hline & Mean +/- SD & $8.9+/-0.9$ & $2.3+/-1.0$ & $26.7+/-11.8$ & $86.0+/-7.9$ \\
\hline & $p$ values & & 0.017 & & 0.018 \\
\hline
\end{tabular}

VAS: visual analogue score, $S D$ : standard deviation.

Only four case reports were published in the literature to our knowledge of the use of $\mathrm{HemiCAP}^{\circ}$ for femoral head pathologies. In the first study, Jäger et al. reported successful results in a 22-year-old female patient having traumatic osteonecrosis of the femoral head, with one-year follow-up [52]. In a second study, partial resurfacing was performed successfully following a subcapital femoral varus osteotomy in a 16-year-old male patient, with a two-year follow-up [53]. In a study of Mahmud et al., a 24-year-old male with osteochondral defect of the femoral head was successfully treated with HemiCAP ${ }^{\circ}$, with five-years follow-up [54]. Recently, a patient having an osteochondral lesion of the hip, who was treated with partial femoral resurfacing, has been reported with the longest follow-up of six years [55].
To our knowledge, the present study is the first report of a consecutive case series with the use of HemiCAP for the treatment of focal ON of the femoral head. But, there are some limitations of this study, which should be discussed. Firstly, this study compromises a small number of patients, but this is not a common condition and large studies are difficult to do to collect enough cases. Another limitation is the retrospective evaluation of the prospectively collected data. A prospective, multi-center study evaluating this procedure over a long term would give more definitive results. However, the procedure seems to have some promise in the treatment of osteonecrosis with advanced stages and collapse or as a salvage of other failed procedures. The biggest advantage is that the anatomy is preserved so that future procedures are not compromised.

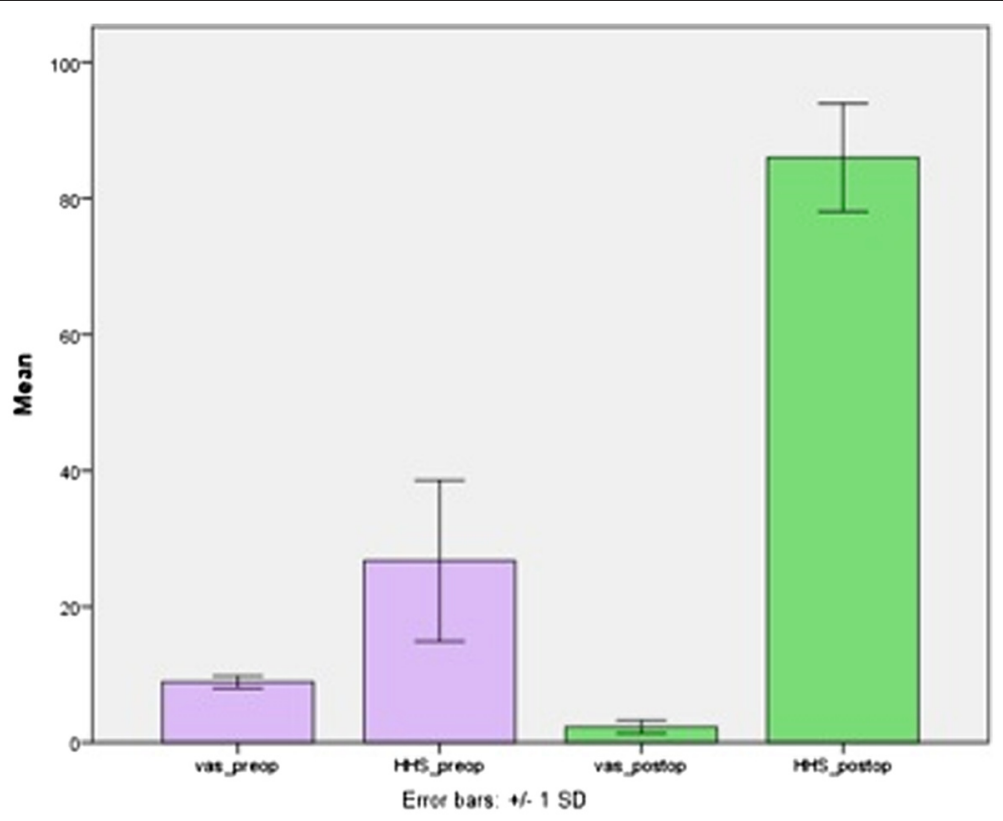

Figure 9 Mean VAS and Harris Hip Scores. Mean values (+/-SD, longitudinal lines) of preoperative (purple bar) and postoperative second year (green bar) VAS and Harris Hip Scores (VAS = visual analogue score, HHS = Harris Hip Score, preop. = preoperative, postop. = postoperative). 


\section{Conclusions}

As a result, the optimal and ideal treatment for the focal osteonecrosis of the femoral head has not been established, especially for young and middle-aged patients. Although THA is often used for these patients, implant longevity and subsequent revisions have still been problems in these age groups. To the best of our knowledge, this study is the first case series in the literature, reporting successful clinical results with the use of an alternative focal, anatomic, limitedresurfacing implant $\left(\mathrm{HemiCAP}^{\oplus}\right)$ for the femoral head and joint preserving treatment of focal osteonecrosis, and we would recommend it as a potential alternative treatment option for these patients.

\section{Abbreviations}

ON: osteonecrosis; ROM: range of motion; MRI: magnetic resonance imaging; R: right; L: left; ITP: idiopathic thrombocytopenic purpura; VAS: visual analogue score; HHS: Harris Hip Score; SD: standard deviation; THA: total hip arthroplasty.

\section{Competing interests}

AM reports his Arthrosurface royalties. All the other authors declare that they have no competing interests.

\section{Authors' contributions}

OB has made substantial contributions to conception and design, contributed to the acquisition of data, analysis and interpretation of data, carrying out of the surgeries, drafting of the manuscript and carrying out of its revision and has given the final approval of the version to be published. MND helped draft the manuscript and revised it critically for important intellectual content, has participated in its design and coordination, and has given the final approval of the version to be published. MY and NK helped draft the manuscript. AM has made substantial contributions to conception and design, helped draft the manuscript and revised it critically for important intellectual content, has participated in its design and coordination, and has given the final approval of the version to be published. All authors read and approved the final version of the final manuscript.

\section{Author details}

${ }^{1}$ Department of Orthopaedics and Traumatology, Konya Necmettin Erbakan University, Meram Faculty of Medicine, Meram 42080, Konya, Turkey. ${ }^{2}$ Department of Orthopaedics and Traumatology, Hacettepe University, Faculty of Medicine, 06230 Ankara, Turkey. ${ }^{3}$ Cleveland Clinic Sports Health Center, 5555 Transportation Blvd, Garfield Heights, Ohio 44125, USA.

Received: 13 February 2015 Accepted: 15 April 2015

\section{Published online: 28 April 2015}

\section{References}

1. Mont MA, Hungerfort DS. Non-traumatic avascular necrosis of the femoral head. J Bone Joint Surg Am. 1995;77:459-74

2. Jones LC, Hungerford DS. Osteonecrosis: etiology, diagnosis, and treatment. Curr Opin Rheumatol. 2004;16:443-9.

3. Zalavras CG, Lieberman JR. Osteonecrosis of the femoral head: evaluation and treatment. J Am Acad Orthop Surg. 2014;22:455-64.

4. Pivec IK, Kapadia BH, Banerjee S, Mont MA. Osteonecrosis of the femoral head. Bone Joint J. 2013;95-B(Suppl A):46-50002E.

5. Lee JS, Lee JS, Rob HL, Kim CH, Js J, Suh KT. Alteration in the differentiation ability of mesenchymal stem cells in patients with nontraumatic osteonecrosis of the femoral head: comparative analysis according to the risk factor. J Orthop Res. 2006;24(4):604-9.

6. Liebermann JR, Berry DJ, Mont MA, Aaron RK, Callaghan JJ, Rajadhyaksha $A D$, et al. Osteonecrosis of the hip: management in the 21st century. Instr Course Lect. 2003:52:337-55.

7. Zibis AH, Karantanas AH, Roidis NT, Hantes ME, Argiri P, Moraitis T, et al. The role of MR imaging in staging femoral head osteonecrosis. Eur J Radiol. 2007;63(1):3-9.
8. Ficat RP, Arlet J. Forage-biopsie de la tete femorale dans l'osteonecrose primitive. Observations histo-pathologiques portant sur huit forages. Rev Rheum. 1964;31:257-64.

9. Ficat RP. Idiopathic bone necrosis of the femoral head: early diagnosis and treatment. J Bone Joint Surg (Br). 1985;67:3-9.

10. Jawad MU, Haleem AA, Scully SP. In brief: Ficat classification: avascular necrosis of the femoral head. Clin Orthop Relat Res. 2012;470:2636-9.

11. Steinberg ME, Hayken GD, Steinberg DR. A quantitative system for staging avascular necrosis. J Bone Joint Surg (Br). 1995;77(1):34-41.

12. Ha YC, Jung WH, Kim JR, Seong NH, Kim SY, Koo KH. Prediction of collapse in femoral head osteonecrosis: a modified Kerboul method with use of magnetic resonance images. J Bone Joint Surg Am. 2006;88 Suppl 3:35-40.

13. Mont MA, Carbone JJ, Fairbank AC. Core decompression versus nonoperative management for osteonecrosis of the hip. Clin Orthop Relat Res. 1996;324:169-78.

14. Lai KA, Shen WJ, Yang CY, Shao CJ, Hsu JT, Lin RM. The use of alendronate to prevent early collapse of the femoral head in patients with nontraumatic osteonecrosis: a randomized clinical study. J Bone Joint Surg Am. 2005;87(10):2155-9.

15. Chen CH, Chang JK, Lai KA, Hou SM, Chang CH, Wang GJ. Alendronate in the prevention of collapse of the femoral head in nontraumatic osteonecrosis: a two-year multicenter, prospective, randomized, double-blind, placebo study. Arthritis Rheum. 2012;64(5):1572-8

16. Glueck CJ, Freiberg RA, Sieve L, Wang P. Enoxaparin prevents progression of stages I and II osteonecrosis of the hip. Clin Orthop Relat Res. 2005;435:164-70

17. Ajmal M, Matas AJ, Kuskowski M, Cheng EY. Does statin use reduce the risk of corticosteroid-related osteonecrosis in renal transplant population? Orthop Clin North Am. 2009;40:235-9.

18. Disch AC, Matziolis G, Perka C. The management of necrosis-associated and idiopathic bone-marrow oedema of the proximal femur by intervenous iloprost. J Bone Joint Surg (Br). 2005;87:560-4.

19. Wang CJ, Wang FS, Huang CC, Yang KD, Weng LH, Huang HY. Treatment for osteonecrosis of the femoral head: comparison of extracorporeal shock waves with core decompression and bone grafting. J Bone Joint Surg Am. 2005;87(11):2380-7.

20. Masssari L, Fini M, Cadossi R, Setti S, Traina GC. Biophysical stimulation with pulsed electromagnetic fields in osteonecrosis of the femoral head. J Bone Joint Surg Am. 2006;88-A(Suppl):56-60.

21. Camporesi EM, Vezzani G, Bosco G, Mangar D, Bernasel TL. Hyperbaric oxygen therapy in femoral head avascular necrosis. J Arthroplasty. 2010;25(Suppl):118-23.

22. Buckley PD, Gearen PF, Petty RW. Structural bone-grafting for early atraumatic avascular necrosis of the femoral head. J Bone Joint Surg Am. 1991;73:1357-64.

23. Gangji V, De Maertelaer V, Hauzer JP. Autologous bone marrow cell implantation in the treatment of non-traumatic osteonecrosis of the femoral head: five year follow-up of a prospective controlled study. Bone. 2011;49:1005-9.

24. Zhao D, Cui D, Wang B, Tian F, Guo L, Yang L, et al. Tretment of early stage osteonecrosis of the femoral head with autologous implantation of bone marrow-derived and cultured stem cells. Bone. 2012;50:325-30.

25. Ibrahim V, Dowling H. Platelet-rich plasma as a nonsurgical treatment option for osteonecrosis. PM R. 2012;4:1015-9.

26. Lieberman JR, Conduah A, Urist MR. Treatment of osteonecrosis of the femoral head with core decompression and human bone morphogenetic protein. Clin Orthop Relat Res. 2004;429:139-45.

27. Urbaniak JR, Coogan PG, Gunneson EB, Nunley JA. Treatment of osteonecrosis of the femoral head with free vascularized fibular grafting. A long-term follow-up study of one hundred and three hips. J Bone Joint Surg Am. 1995;77:681-94.

28. Veilette CJ, Mehdian H, Schemitsch EH, McKee MD. Survivorship analysis and radiographic outcome following tantalum rod insertion for osteonecrosis of the femoral head. J Bone Joint Surg Am. 2006;88 suppl 3:48-55.

29. Mont MA, Fairbank AC, Krackow KA, Hungerford DS. Corrective osteotomy for osteonecrosis of the femoral head. J Bone Joint Surg Am. 1996;78(7):1032-8.

30. Muraki M, Sudo A, Hasegawa M, Fukuda A, Uchida A. Long-term results of bipolar hemiarthroplasty for osteoarthritis of the hip and idiopathic osteonecrosis of the femoral head. J Orthop Sci. 2008;13:313-7. 
31. Kabata T, Maeda T, Tanaka K, Yoshida H, Kajino Y, Horii T, et al Hemi-resurfacing versus total resurfacing for osteonecrosis of the femoral head. J Orthop Surg. 2011;19:177-80.

32. Kim YH, Js K, Park JW, Joo JH. Contemporary total hip arthroplasty with or without cement in patients with osteonecrosis of the femoral head: a concise follow-up, at an average of seventeen years, of a previous report. J Bone Joint Surg Am. 2011;93:1806-10.

33. Ganz R, Gill TJ, Gautier E, Ganz K, Krügel N, Berleman U. Surgical dislocation of the adult hip a technique with full access to the femoral head and acetabulum without the risk of avascular necrosis. J Bone Joint Surg (Br). 2001;83-B:1119-24

34. Lavernia CJ, Sierra RJ. Core decompression in atraumatic osteonecrosis of the hip. J Arthroplasty. 2000;15:171-8.

35. Banerjee S, Issa K, Pivec R, Kapadia BH, Khanuia HS, Mont MA. Osteonecrosis of the hip: treatment options and outcomes. Orthon Clin N Am. 2013:44:463-76.

36. Amanatullah DF, Strauss EJ, Di Cesare PE. Current management of options for osteonecrosis of the femoral head: part II. Operative management Am J Orthop. 2011;40(10):216-25.

37. Lee MS, Hsieh PH, Chang YH, Chan YS, Agrawal S, Ueng SW. Elevated intraosseous pressure in the intertrochanteric pressure in the intertrochanteric region is associated with poorer results in osteonecrosis of the femoral head treated by multiple drilling. J Bone Joint Surg (Br). 2008;90:852-7.

38. Berend KR, Gunneson EE, Urbaniak JR. Free vascularized fibular grafting for the treatment of postcollapse osteonecrosis of the femoral head. J Bone Joint Surg Am. 2003;85-A(6):987-93.

39. Eward WC, Rineer CA, Urbaniak JR, Richard MJ, Ruch DS. The vascularized fibular graft in precollapse osteonecrosis: is long-term hip preservation possible? Clin Orthop Relat Res. 2012;470(10):2819-26.

40. Ortiguera CJ, Pulliam IT, Cabanela ME. Total hip arthroplasty for osteonecrosis: matched-pair analysis of 188 hips with long-term follow-up. J Arthroplasty. 1999;14(1):21-8.

41. Kim YH, Oh SH, Kim JS, Koo KH. Contemporary total hip arthroplasty with and without cement in patients with osteonecrosis of the femoral head. J Bone Joint Surg Am. 2003;85(4):675-81.

42. Radl R, Hungerford M, Materna W, Rehak P, Windhager R. Higher failure rate and stem migration of an uncemented femoral component in patients with femoral head osteonecrosis than in patients with osteoarthritis. Acta Orthop. 2005;76(1):49-55.

43. Brinker MR, Rosenberg AG, Kull L, Galante JO. Primary total hip arthroplasty using noncemented porous-coated femoral components in patients with osteonecrosis of the femoral head. J Arthoplasty. 1994;9:457-68.

44. Hartley WT, McAuley JP, Culpepper WJ, Engh Jr CA, Engh Sr CA Cementless total hip arthroplasty for hip osteonecrosis. J Bone Joint Surg Am. 2000;84:1100

45. Beaulé PE, Dorey FJ. Survivorship analysis of cementless total hip arthroplasty in younger patients. J Bone Joint Surg Am. 2001;83:1590-1.

46. Taylor AH, Shannon M, Whitehouse SL, Lee MB, Learmonth ID. Harris Galante cementless acetabular replacement in avascular necrosis. J Bone Joint Surg (Br). 2001:83:177-82

47. Leuning M, Ganz R. The evolution and concepts of joint-preserving surgery of the hip. Bone Joint J. 2014;96-B:5-18.

48. Mont MA, Rajadhyaksha AD, Hungerford DS. Outcomes of limited femoral resurfacing arthroplasty compared with total hip arthroplasty for osteonecrosis of the femoral head. J Arthroplasty. 2001;16(8 Suppl 1):134-9.

49. Beaulé PE, Amstutz HC, Le Duff M, Dorey F. Surface arthroplasty for osteonecrosis of the hip: hemi-resurfacing versus metal-on-metal hybrid resurfacing. J Arthroplasty. 2004;27:54-8.

50. Squire M, Fehring TK, Odum S, Griffin WL, Bohannon MJ. Failure of femoral surface replacement for femoral head avascular necrosis. J Arthroplasty. 2005;20:108-14.

51. Marker DR, Seyler TM, Jinnah RH, Delanois RE, Ulrich SD, Mont MA Femoral neck fractures after metal-on-metal total hip resurfacing: a prospective cohort study. J Arthroplasty. 2007;22(7, suppl 3):66-71.

52. Jäger M, Begg MJW, Krauspe R. Partial hemi-resurfacing of the hip joint - a new approach to treat local osteochondral defects? Biomed Tech. 2006;51:371-6.

53. Van Stralen RA, Haverkamp D, Van Bergen CJA, Eijer H. Partial resurfacing with varus osteotomy for an osteochondral defect of the femoral head. Hip Int. 2009;19(1):67-70.
54. Mahmud T, Naudie DDR. Partial hip resurfacing for an osteochondral defect of the femoral head. J Bone Joint Surg Case Connect. 2012;2, e14.

55. Lea MA, Barkatali B, Porter ML, Board TN. Osteochondral lesion of the hip treated with partial femoral head resurfacing. Case report and six-year follow-up. Hip Int. 2014 Apr 17:0. doi: 10.5301/hipint.5000121. [Epub ahead of print].

\section{Submit your next manuscript to BioMed Central and take full advantage of:}

- Convenient online submission

- Thorough peer review

- No space constraints or color figure charges

- Immediate publication on acceptance

- Inclusion in PubMed, CAS, Scopus and Google Scholar

- Research which is freely available for redistribution

Submit your manuscript at www.biomedcentral.com/submit 